Eixo Temático: Relação entre Ciência, Educação e Cultura

\title{
ET-05-003 \\ ANÁLISE DO FILME “O MAR NÃO ESTÁ PRÁ PEIXE” COMO RECURSOS DIDÁTICOS NO ENSINO DE CIÊNCIAS E BIOLOGIA
}

\author{
Anderson Antonio da Silva ${ }^{1}$, Vagne de Melo Oliveira² \\ ${ }^{1}$ Graduando do curso de Licenciatura em Ciências Biológicas, Universidade Federal Rural de \\ Pernambuco. E-mail: anderson_portnoy@hotmail.com. \\ 2Doutor em Ciências Biológicas pelo Programa de Pós-Graduação em Ciências Biológicas.
}

http://dx.doi.org/10.21472/congrebio2016.et-05-003

\section{RESUMO}

Os peixes ósseos provavelmente originaram-se de ancestrais do siluriano e tornaram-se o maior grupo vivente de vertebrados. De grande significado para a história evolutiva é o fato de que, não muito tempo depois desta classe ter-se diferenciado, ela dividiu-se em duas linhas de desenvolvimento. Uma delas levou ao grupo mais sucedido, os Actinopterygii, ou peixes de nadadeiras raiadas. A outra linha, os Sarcopterygii ou peixes de nadadeiras carnosas, deram origem aos vertebrados terrestres. Em relação aos tubarões, eles são carnívoros consumidores, dominando os níveis superiores das cadeias alimentares marinhas. Predadores versáteis e efetivos, alimentando-se tanto de presas pequenas quanto grandes. Os seres vivos apresentam estruturas biológicas que muitas vezes são de difícil compreensão para estudantes, necessitando de estratégias didáticas para facilitar o entendimento pelo aluno. Existem várias estratégias e métodos para o ensino, tais como modelos, analogias, metáforas, descrições, entre outras. Na maioria das escolas públicas brasileiras, os livros didáticos (LD) são os principais materiais disponíveis aos estudantes, tanto para estudos quanto para pesquisas. O antropomorfismo é uma pratica muito antiga. Ele pode ser muito notado na cultura do cristianismo. Podemos também perceber a presença do antropomorfismo na mitologia grega. Ele é usado para passar ou fundamentar argumentos, contos, lição/senso de moral e narrativas em diversas sociedades ou comunidades. Tal recurso é utilizado normalmente para passar mensagens metafóricas que podem possuir uma vertente religiosa, moral ou social. Essa atribuição da figura humana pode ser "transferida" a qualquer constituinte da realidade (animais, vegetais, figuras imagináveis, carros, objetos inanimados, ou elementos tangíveis). Muito ao se deparar com o a palavra antropomorfismo ligam logo ao publico infantil, contudo atualmente o publico que foi conquistado pelas novas tendências incluem adultos. O presente estudo teve como objetivo averiguar os assuntos relacionado a conceitos zoológicos, antropomórficos, fisiológicos, morfológicos e ecológicos do Filo Cordata e da Classe Pisces, no filme O Mar não está ará Peixe para seu manuseio no ensino de Ciências e Biologia, percebendo a qualidade e a quantidade e dos conteúdos apresentados e a forma como foram levantadas seguindo critérios pré-definidos pelos autores do trabalho. Para assegurar uma melhor compreensão dos vários critérios analisados e focando em informações quantitativas preferiu-se ao elaborar tabelas subdividi-la nas suas respectivas áreas da Biologia e/ou ciências. O grau de antropomorfismo em relação à outros filmes com mesma intensão é relativamente aceitável. O filme é muito abrangente, fala de diversidades de grupos e peixes, fala da interação ou intervenção humana no local, tanto de pesca, de poluição, e cuidado de biólogos ou turistas.

Palavras-chave: Filmes e animação; Ensino de Biologia e Ciências; O Espanta Tubarões. 


\section{INTRODUÇÃO}

Os vertebrados são um grupo de animais diversificado e fascinante que se caracterizam pela presença de vertebras arranjadas em série formando a coluna vertebral. As vértebras formam-se em torno da notocorda durante o desenvolvimento, como também circundam o tubo nervoso. São divididos em dois grandes grupos zoológicos: Peixes e Tetrápodes (anfíbios, sauropsida e mamíferos), destes os peixes é o grupo mais diversificado e numeroso, com aproximadamente 27.000 espécies viventes. Podem ser encontrados em praticamente todos os habitats aquáticos apresentando hábitos e formas variadas (SZPILMAN, 2000; POUGH et al., 2008).

O grande grupo dos peixes pode ser subdividido em: ciclóstomos (peixes com boca circular e sem maxila) e gnatostomados (peixes com maxila e dois conjuntos de nadadeiras pares). Os ciclóstomos são representados pelas feiticeiras (Myxinoidea) e lampreias (Petromyzontoidea). Em geral as feiticeiras e lampreias são peixes com boca circular e sem maxila, são alongados e medem menos de um metro de comprimento, não possuem dutos reprodutivos especializados e a fecundação é externa (POUGH et al., 2008; KARDONG, 2011).

Os gnatostomados são representados pelos peixes cartilaginosos (Chondrichthyes) e pelos peixes ósseos (Osteichthyes). Os Chondrichthyes surgiram no final do devoniano e tornaram-se um grupo bem sucedido passando a dominar os mares. Acredita-se que os Placodermis (primeiros peixes com mandíbulas) podem ter dado origem aos peixes cartilaginosos pela perda da armadura óssea e do endoesqueleto ósseo. Os Chondrichthyes são divididos em dois grandes grupos: os Elasmobranchii (Gr. Elasmo = placa e branchi = brânquias) e os Holocephalii (Gr. holo = inteiro e cephalus = cabeça). Os Elasmobranchii possuem aberturas branquiais múltiplas em cada lado da cabeça e seus representantes são os tubarões e raias (SZPILMAN, 2000; POUGH et al., 2008; KARDONG, 2011).

Ao longo de sua história evolutiva, os tubarões têm sido carnívoros consumidores, dominando os níveis superiores das cadeias alimentares marinhas. São predadores versáteis e efetivos, alimentando-se tanto de presas pequenas quanto grandes. Para capturar suas presas contam com sistemas sensoriais refinados e diversificados, tais como: órgãos neuromastos, ampolas de Lorenzini, responsáveis pela detecção de potenciais elétricos e pequenas diferenças de temperatura, além destes, apresentam extraordinária recepção química, visão bem desenvolvida, especialmente em baixa luminosidade e o sistema da linha lateral, altamente eficiente na deteç̧ão de vibrações, tais como aquelas produzidas por um peixe agonizando (POUGH et al., 2008).

Os Osteichthyes ou peixes ósseos provavelmente originaram-se de ancestrais do siluriano e tornaram-se o maior grupo vivente de vertebrados (POUGH et al., 2008). De grande significado para a história evolutiva é o fato de que, não muito tempo depois desta classe ter-se diferenciado, ela dividiu-se em duas linhas de desenvolvimento. Uma delas levou ao grupo mais sucedido, os Actinopterygii, ou peixes de nadadeiras raiadas. A outra linha, os Sarcopterygii ou peixes de nadadeiras carnosas, deram origem aos vertebrados terrestres (SZPILMAN, 2000).

O peixe é fonte rica em proteínas de fácil absorção e uma grande variedade de vitaminas (tiamina, riboflavina, niacina) e minerais (cálcio, ferro, fósforo, iodo), contribuindo com um quarto da oferta mundial de proteína de origem animal. Possui altos níveis de ácidos graxos poliinsaturados, especialmente ômega-3, que diminui as taxas de colesterol no sangue (DELGADO et al., 2003). São ectotérmicos, sua temperatura flutua de acordo com a temperatura do meio. Estão adaptados para viver na água doce ou salgada. A maioria tem nadadeiras, sustentadas por raios ou espinhos. Quase todos possuem escamas, que tem a função de proteger e cobrir o corpo. Existem três classes de peixes: agnatha, cartilaginosos e os ósseos (HILDEBRAND e GOSLOW, 2006; VANIEL e BEMVENUTI, 2006).

Os seres vivos apresentam estruturas biológicas que muitas vezes são de difícil compreensão para estudantes, necessitando de estratégias didáticas para facilitar o entendimento pelo aluno. Existem várias estratégias e métodos para o ensino, tais como modelos, analogias, metáforas, descrições, entre outras (SANTOS et al., 2011). Na maioria das escolas públicas 
brasileiras, os livros didáticos (LD) são os principais materiais disponíveis aos estudantes, tanto para estudos quanto para pesquisas. São eles que, dentro da área de biologia, compõem grande parte do acervo das bibliotecas dessas escolas (SILVEIRA et al., 2013).

$\mathrm{O}$ antropomorfismo é uma pratica muito antiga. Ele pode ser muito notado na cultura do cristianismo. Podemos também perceber a presença do antropomorfismo na mitologia grega. Ele é usado para passar ou fundamentar argumentos, contos, lição/senso de moral e narrativas em diversas sociedades ou comunidades. Tal recurso é utilizado normalmente para passar mensagens metafóricas que podem possuir uma vertente religiosa, moral ou social. Essa atribuição da figura humana pode ser "transferida" a qualquer constituinte da realidade (animais, vegetais, figuras imagináveis, carros, objetos inanimados, ou elementos tangíveis). Muito ao se deparar com o a palavra antropomorfismo ligam logo ao publico infantil, contudo atualmente o publico que foi conquistado pelas novas tendências incluem adultos.

Claramente, essa tendência para a antropomorfizar animais ou objetos inanimados é e alvo e fonte para a criação de erros. Para alguns o antropomorfismo estar tão ligado ao seu dia a dia que a oposição dessa situação em alguns casos pode ser classificada como desumanização, ou seja, ao tratar um animal de forma diferente de uma pessoa, ele pode ser considerado desumano e sem coração. E na historia isso também pode ser percebido no caso de discriminação, ou seja, certa classe ou grupo social não ser considerado humano, um exemplo que ficou marcado na historia foi à perseguição nazista que por esse processo de desumanização fez atrocidades. Enfim após esse ultimo comentário podemos perceber que a antropomorfização pode ter seu lado positivo, mas também pode ter consequências desastrosas.

O presente estudo teve como objetivo analisar o conteúdo do Filo Cordata e da Classe Pisces, em livros didáticos de Biologia do Ensino Médio, observando a quantidade e a qualidade das informações apresentadas e a forma como foram abordadas seguindo critérios pré-definidos.

\section{“O MAR NÃO ESTÁ PRÁ PEIXE” (SINOPSE E DETALHES)}

Pê é um simpático peixinho órfão, que chegou recentemente a um belo recife e está em busca de sua tia Pérola. Logo ele começa a se enturmar com os moradores locais e se apaixona por Cordélia, uma peixinha cor-de-rosa que atrai as atenções de todos os peixes. Troy, um perigoso tubarão, também está interessado em Cordélia. Para proteger Cordélia, Pê decide enfrentar Troy e fazer com que o recife fique livre de uma vez por todas de sua ameaça" (http://www.adorocinema.com/filmes/filme-125776/). Ano de lançamento 2007.

O filme "O Mar não está prá Peixe" inicia-se abordando o assunto da poluição onde uma família de Peixes discute se vão ou não migrar para os corais (onde as aguas são limpas). $\mathrm{O}$ lugar de inicio do filme ainda possui a intervenção humana com pescas também, e é aí onde o protagonista do filme, Pê, se separa de seus pais (pois eles são pescados). O peixe então passa por um momento de migração de local juntamente com uma família de botos (golfinhos), e ele faz uma amizade com um desses, até chegar nos corais ele se torna um jovem peixe onde seu tamanho não vai variar muito. Neste momento já podemos constatar um erro onde o filme passar a mensagem que existe diferença entre botos e golfinhos, mesmo sem dar nenhuma explicação.

\section{OBJETIVOS}

\section{Objetivo geral}

Averiguar os assuntos relacionado à conceitos zoológicos, antropomórficos, fisiológicos, morfológicos e ecológicos do Filo Cordata e da Classe Pisces, na animação O Espanta Tubarões para seu manuseio no ensino de Ciências e Biologia, percebendo a qualidade e a quantidade e dos conteúdos apresentados. 


\section{Objetivos Específicos}

Pesquisar a Classe Pisces entre outras comparando a relação entre elas no filme "O Mar não está prá Peixe”;

Sondar e observar conceitos antromórficos e de senso comum no filme “O Mar não está prá Peixe"; Biologia.

Argumentar sobre o uso do filme "O Mar não está prá Peixe” em aulas de Ciências e

\section{METODOLOGIA}

Analisou-se os conteúdos relativos à Superclasse Pisces, contidos no seguinte filme: $\mathbf{O}$ Mar não está prá Peixe (2007). Verificando critérios relativos aos conceitos zoológicos, antropomórficos, fisiológicos, morfológicos e ecológicos referentes à superclasse em análise, se há a presença de conceitos errados ou não; e se existe alguma influência do senso comum. Afim de assegurar uma melhor compreensão dos vários critérios analisados e focando em informações quantitativas preferiu-se ao elaborar as tabelas subdividi-la nas áreas da Biologia como: morfológica, fisiologia, ecológica, hábitos, habitat e antropomórfica. Em relação a informações qualitativas podem ser encontradas nos textos logo abaixo de suas respectivas tabelas, mesmo as tabelas sendo claras estão intrinsecamente relacionadas com os textos facilitando a compreensão do assunto dissertado.

\section{RESULTADOS E DISCUSSÃO}

Tabela 1. Indicação de alguns critérios morfológicos contidos ou não no filme "O Mar não está prá Peixe”.

\begin{tabular}{|c|c|}
\hline \multicolumn{2}{|c|}{ Conteúdos relacionados à morfologia } \\
\hline Critérios & Contém \\
\hline \begin{tabular}{c} 
Possuem deformações morfológicas? \\
Sim (baixa) \\
\hline A imagem de algum peixe é distorcida devido a deformidades \\
morfológicas?
\end{tabular} & Não \\
\hline $\begin{array}{c}\text { A deformidade morfológica esta ligada ao antropomorfismo? } \\
\text { Tais deformidades induzem interpretação(s) incorreta(s) sobre } \\
\text { peixes? }\end{array}$ & Não \\
\hline
\end{tabular}

No filme podemos encontrar alguns peixes com sobrancelhas ou cílios. Também possuem ligeiramente uma breve acentuação de características possivelmente por questão de estética e design, ou seja, os lábios de personagens fêmeas tem traços que chegam próximo a da boca de uma mulher, assim como parecerem estar de batom. Ou detalhe e que as nadadeiras superiores em algumas poucas situações são utilizadas como se fossem braços, mesmo sem a presença de deformidades morfológicas ou anatômicas. Claramente tais deformidades estão totalmente ligadas ao antropomorfismo. 
Tabela 2. Indicação de alguns critérios fisiológicos contidos ou não no filme "O Mar não está prá Peixe”.

\begin{tabular}{|c|c|}
\hline \multicolumn{2}{|c|}{ Conteúdos relacionados à fisiologia. } \\
\hline Critérios & Contém \\
\hline Possui erros fisiológicos gritantes em algum peixe? & Sim \\
\hline O erro fisiológico é apresentado muitas vezes? & Sim \\
\hline $\begin{array}{c}\text { O(s) erro(s) fisiológico(s) têm o objetivo de passar uma ideia mais “aceitável” } \\
\text { sobre peixes? }\end{array}$ & Sim \\
\hline A deformidade fisiológica esta ligada ao antropomorfismo? & Sim \\
\hline O filme passa alguma explicação para fortalecer o erro fisiológico? & Não \\
\hline
\end{tabular}

No “O Mar não está prá Peixe”, pê (protagonista) aprender a "jogar bolas” de água contra seus adversários ou alvos, o mesmo aprende com seu mestre, Senhor Tortuga (uma tartaruga - um sauropsida). Além disso o antagonista (Troi - um Tubarão Tigre) se apaixona por Cordélia (um peixe ósseo de pequeno porte). Os erros descritos são exibidos várias vezes durante todo o filme, o que leva a certa fixação dos conceitos equivocados por parte de quem estar assistindo. Os erros fisiológicos apresentados, sem dúvida, foram formulados com a intenção de passar uma ideia de maior “aprovação"; além do peixe protagonista que aprende a "lutar” para se defender e confrontar um tubarão.

Tabela 3. Indicação de alguns critérios ecológicos, hábitos e de habitats contidos ou não no filme “O Mar não está prá Peixe”.

\begin{tabular}{|c|c|}
\hline \multicolumn{2}{|c|}{ Conteúdos relacionados à ecologia, hábitos e habitat. } \\
\hline Critérios & Contém \\
\hline Apresenta peixes fora de seu habitat? & Sim \\
\hline O habitat possui deformidades? & Não \\
\hline $\begin{array}{c}\text { grup̧osos? } \\
\text { Apresenta alguma relação ou interaca dos peixes com outros }\end{array}$ \\
\hline Mostra alguma relação/interação humana no meio? & Sim \\
\hline Abordar assuntos ecológicos (como poluição)? & Sim \\
\hline Observa-se diversidade de espécies e grupos? & Sim \\
\hline
\end{tabular}

Contendo uma variedade relativa de espécies de peixes e de outros grupos animais, o filme torna-se rico. Contudo, cabe ao telespectador fazer as diferenciações entre grupos, em momento algum fica claro o grupo zoológico de cada personagem do filme. Entre outros grupos podemos destacar: crustáceos (lagostas, camarões, siris, caranguejos, ...), cnidários (água-viva), moluscos (ostras, mexilhões, lulas e polvos) e equinodermos (estrela do mar). Dentre os principais equívocos queremos destacar o seguinte ponto:

Temos a presença de um golfinho, e um leão marinho em pleno recife de corais. Os mamíferos marinhos que podem ser confundidos ou classificados como peixes, uma vez que o filme não faz nenhuma diferenciação entre os grupos.

Percebe-se uma interação humana com os animais, tanto de biólogos como de pescadores. O início do filme aborda o assunto de poluição e durante o filme fala sobre pesca também. O que pode auxiliar ou ser ponto de partida para o professor abordar e socializar temas gerais e transversais da ciência e biologia como por exemplo: poluição, pescas ilegais, relação homem e peixes. 
Tabela 4. Indicação de alguns critérios antropomórficos contidos ou não no filme "O Mar não está prá Peixe”.

\begin{tabular}{|c|c|}
\hline \multicolumn{2}{|c|}{ Conteúdos relacionados à Antropomorfia. } \\
\hline Critérios & Contém \\
\hline Contém Antropomorfismo? & Sim \\
\hline Possui cidades, escolas, prédio, entre outras coisas? & Sim \\
\hline Observa-se nos personagens a demonstração de sentimentos (amor, raiva, \\
alegria, paixão)? & Sim \\
\hline Divulgam alguma mensagem do senso comum? & Sim \\
\hline O antropomorfismo presente nos personagens altera drasticamente as \\
características de algum peixe? & Não \\
\hline Desmistifica algum erro comum social? & Sim \\
\hline Adequação para entendimento do publico infantil? & Não \\
\hline
\end{tabular}

O antropomorfismo no filme "O Mar não está pra Peixe" está mais ligado e evidente à manifestações de sentimentos, o enredo gira em torno do amor e/ou paixão entre os personagens. Um tubarão (peixe cartilaginoso) e um peixe (ósseo) se "apaixonam” pelo mesmo peixe fêmea. O protagonista é primo de um certo tipo de peixe que lembra muito um baiacu, contudo destacamos que pelas características apresentadas não podemos classifica-lo com toda propriedade, devido algumas deformidades. Ou seja, é comparado a uma outra espécie totalmente diferente como primos o que sugeri uma forte ligação.

\section{CONCLUSÃO}

Ao analisar os conceitos e conteúdos relacionados à Superclasse Pisces encontrados no filme "O mar não estar para peixes” percebe que o grau de antropomorfismo em relação à outros filmes com mesma intensão é relativamente aceitável. Ou seja, o professor facilmente pode desconstruir tais conceitos passados em sala. No filme destacamos um tubarão apaixonado por um peixe comum, o fato de um peixe e uma tartaruga aprenderem e possuírem a capacidade de jogar bolas d'águas. Outro erro encontrado no início do filme é a tentativa diferenciar boto de golfinho. Mas como dito anteriormente o filme é muito abrangente, fala de diversidades de grupos e peixes, fala da interação ou intervenção humana no local, tanto de pesca, de poluição, e cuidado de biólogos ou turistas.

O filme possui alguns erros ao mesmo tempo que contém meios para abordagens de vários temas e assuntos voltados para a classe peixes e ainda pode abordar de forma mais abrangente assuntos transdisciplinares e contextuais. Mas caberá ao professor estar preparado para fazer um processo de sensibilização, norteamento e até mesmo de desconstrução quando necessário. Com isso poderá também motivar alunos críticos-reflexivos, onde podem julgar e analisar erros e acertos do filme.

\section{REFERÊNCIAS}

DELGADO, C. L.; WADA, N.; ROSEGRANT, M. W.; MEIJER, S.; AHMED, M. Outlook for fish to 2020: meeting global demand. Washington, D. C.: International Food Policy Research Institute, 2003.

FELIPE, S. T. Natureza e moralidade. Igualdade antropomórfica, antropocêntrica, ou ética? Philosophica, v. 25, $\quad$ p. 43-75, $2005 . \quad$ Disponível em: $<$ http://www.centrodefilosofia.com/uploads/pdfs/philosophica/25/4.pdf>. Acesso em: 04 mar. 2016. 
HILDEBRAND, M.; GOSLOW, G. Análise da estrutura dos vertebrados. São Paulo: Atheneu, 2006.

KARDONG, K. V. Vertebrados: anatomia comparada, função e evolução. São Paulo: Roca, 2011.

POUGH, F. H.; JANIS, C. M.; HEISER, J. B. A vida dos vertebrados. 4 ed. São Paulo: Atheneu, 2008.

SANTOS, S. C. S.; TERAN, A. F.; SILVA-FORSBERG, M. C. Analogias em livros didáticos de Biologia no ensino de Zoologia. Investigações em Ensino de Ciências, v. 15, n. 3, p. 591603, 2011.

SILVEIRA, E. L.; GEALH, A. M.; MORALES, A. G.; CALDEIRA, C. S. Análise do conteúdo de zoologia de vertebrados em livros didáticos aprovados pelo PNLEM 2009. Revista Brasileira de Pesquisa em Educação em Ciências, v. 13, n. 1, p. 217-232, 2013.

SZPILMAN, M. Peixes marinhos do Brasil: guia prática de identificação. São Paulo: MAUAD, 2000. 